\title{
What Happens After Health Coaching? Observational Study 1 Year Following a Randomized Controlled Trial
}

\author{
Anjana E. Sharma, MD \\ Rachel Willard-Grace, MPH \\ Danielle Hessler, PbD \\ Thomas Bodenbeimer, MD, MPH \\ David H. Thom, MD, PbD \\ Center for Excellence in Primary Care, \\ UCSF Department of Family \& Community \\ Medicine, San Francisco, California
}

\begin{abstract}
PURPOSE Health coaching is effective for chronic disease self-management in the primary care safety-net setting, but little is known about the persistence of its benefits. We conducted an observational study evaluating the maintenance of improved cardiovascular risk factors following a health coaching intervention.
\end{abstract}

METHODS We performed a naturalistic follow-up to the Health Coaching in Primary Care Study, a 12-month randomized controlled trial (RCT) comparing health coaching to usual care for patients with uncontrolled diabetes, hypertension, or hyperlipidemia. Participants were followed up 24 months from RCT baseline. The primary outcome was the proportion at goal for at least 1 measure (hemoglobin $\mathrm{A}_{1 \mathrm{c}}$, systolic blood pressure, or LDL cholesterol) that had been above goal at enrollment; secondary outcomes included each individual clinical goal. Chisquare tests and paired t-tests compared dichotomous and continuous measures.

RESULTS 290 of 441 participants (65.8\%) participated at both 12 and 24 months. The proportion of patients in the coaching arm of the RCT who achieved the primary outcome dropped only slightly from $47.1 \%$ at 12 to $45.9 \%$ at 24 months $(P=.80)$. The proportion at goal for hemoglobin $A_{1 c}$ dropped from $53.4 \%$ to $36.2 \%(P=.03)$. All other clinical metrics had small, nonsignificant changes between 12 and 24 months.

CONCLUSIONS Results support the conclusion that most improved clinical outcomes persisted 1 year after the completion of the health coaching intervention.

Ann Fam Med 2016;14:200-207. doi: 10.1370/afm.1924.

\section{INTRODUCTION}

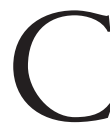
ardiovascular disease and risk factors, including diabetes, hypertension, and hyperlipidemia, are increasing in prevalence in the United States ${ }^{1-4}$ and contribute to growing morbidity and mortality. ${ }^{5}$

Underserved patients, including low-income and racial/ethnic minorities, disproportionately suffer from cardiovascular diseases. ${ }^{6,7}$ Given this disparity, accessible and low-cost interventions are needed, especially in the primary care safety net, which provides the bulk of care for the underserved. ${ }^{8}$

Health coaching, provided by a member of a primary care team trained to support patient engagement in chronic disease self-management, is a promising intervention that helps offset the heavy workload placed on primary care providers for chronic disease management. ${ }^{9}$ Health coaching has been shown to improve outcomes in cardiovascular risk factors including diabetes and hypertension..$^{10-12}$ Since health coaching applies principles of motivational interviewing and goal-setting to influence behavioral change and chronic disease self-management, it may have longer-lasting benefits than traditional interventions such as medications, which are only effective when taken.

To date, the majority of health coaching research has focused on effects limited to the period of active intervention, with little known about the persistence of a positive effect after health coaching has ended. The few studies of post-intervention effects of health coaching that demonstrate some maintenance of effect either were not randomized controlled trials, ${ }^{13}$

\footnotetext{
Anjana E. Sharma, MD 1001 Potrero Avenue, Building 83

San Francisco, CA 94110

Anjana.sharma@ucsf.edu
} 
did not study cardiovascular risk factors, ${ }^{14,15}$ or were not among safety-net populations. ${ }^{16}$ We conducted a pragmatic study to follow up a 1-year randomized controlled trial of a health coaching intervention among a safety-net population to determine whether the significant improvements in control of diabetes, hypertension, and hyperlipidemia were sustained. ${ }^{17}$

\section{METHODS}

We conducted a 12-month observational study of patients after their participation in the Health Coaching in Primary Care study, a 1-year, prospective randomized controlled trial (RCT) of health coaching provided by trained medical assistants for patients with poorly controlled diabetes, hypertension, and/or hyperlipidemia.

The RCT was approved by the University of California, San Francisco Committee on Human Research (approval number 10-02813) and registered with clinicaltrials.gov (NCT01220336). Detailed descriptions of the study methods and findings for the original RCT have already been published..$^{17,18}$

\section{Setting and Participants}

Participants in the observational study were patients who had participated in the original RCT_-patients attending 2 safety-net, adultmedicine primary care clinics in San Francisco, California, serving a predominantly Latino and African-American population (Supplemental Appendix, http:// annfammed.org/content/14/3/200/ suppl/DC1). Patients eligible for the RCT included adult (aged 18 to 75 years) English or Spanish speakers who had telephone access and who planned to come to the clinic for the next year. Patients were included if they had diabetes, hypertension, or hyperlipidemia uncontrolled at baseline, defined as having a hemoglobin $\mathrm{A}_{1 \mathrm{c}}\left(\mathrm{HbA}_{1 \mathrm{c}}\right)$ of at least $8.0 \%$ in the prior 3 months, a systolic blood pressure (SBP) of at least $140 \mathrm{mmHg}$ at baseline and at a previous visit at least 2 weeks but not more than 1 year before baseline, or a low-density lipoprotein (LDL) of at least $160 \mathrm{mg} / \mathrm{dL}$ (if not diabetic) or at least $100 \mathrm{mg} /$ $\mathrm{dL}$ (if diabetic) within 6 months before enrollment.
Intervention Period for the Original Randomized Controlled Trial (Baseline to 12 Months)

Eligible patients were invited to participate in the RCT via letter and follow-up phone call. Those interested in participating provided informed consent and were enrolled and randomized to health coaching or usual care over the next 12 months (Figure 1). Patients randomized to the usual-care arm had access to resources available at their clinic site including primary care, pharmacy, diabetes educators, chronic care nurses, and nutrition counseling. Patients randomized to the intervention arm had access to the services of usual care plus health coaching for 1 year.

Health coaches were 3 diploma-certified Latina medical assistants who were bilingual in English and Spanish. All health coaches received 40 hours of health coach training, the details of which have been published. ${ }^{18,19}$ Health coaches accompanied patients to clinic visits, met with them before encounters with their primary care physician to identify key questions for the visits and review medications, remained in the exam room during the medical visits, reviewed the care plan after visits, and contacted patients by phone between visits. At the 12-month conclusion of the RCT, patients in the health coaching arm were significantly more likely than those in usual care to have

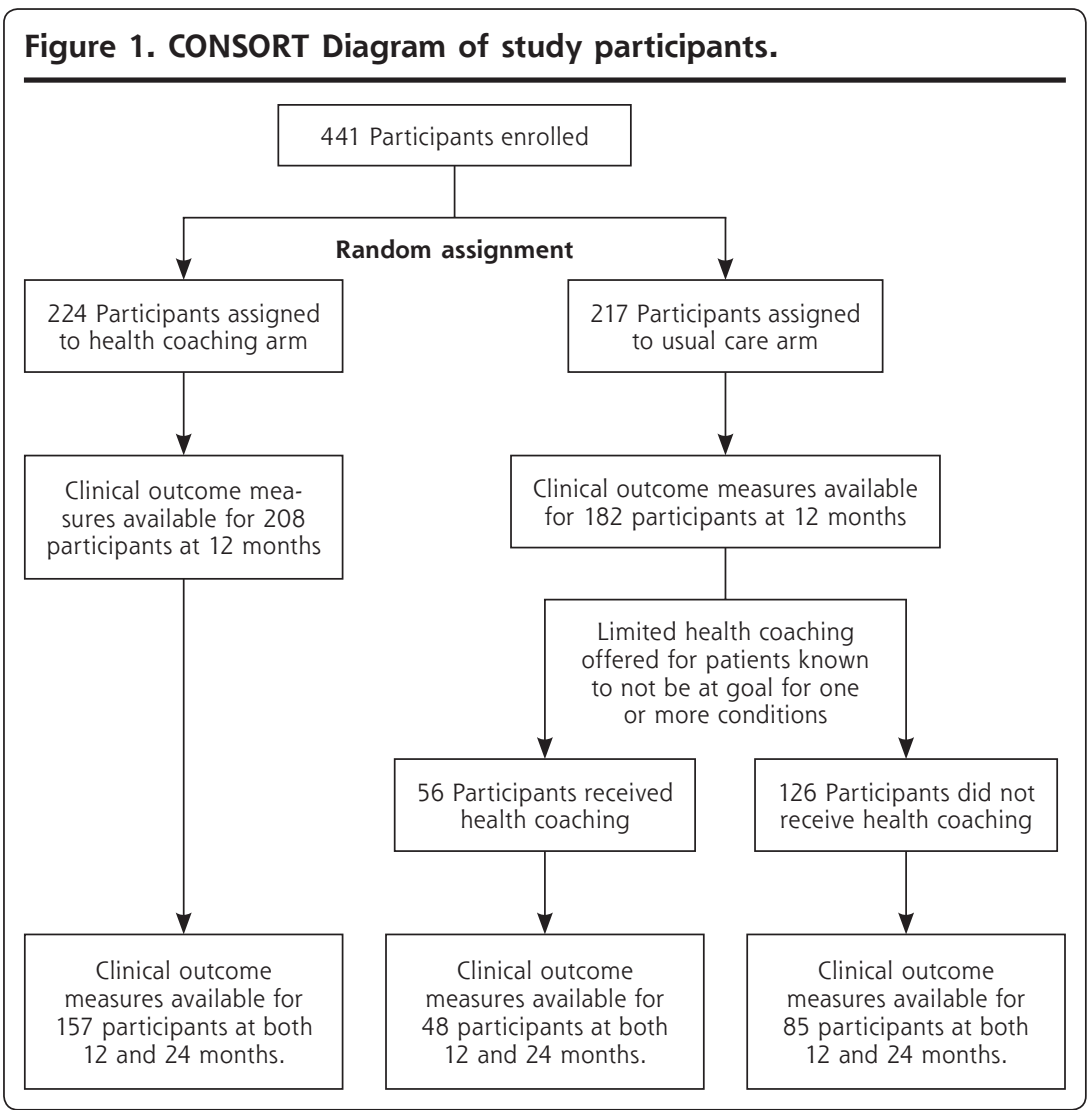


achieved the composite outcome of meeting at least 1 clinical goal for either $\mathrm{HbA}_{1 \mathrm{c}}$ SBP, or LDL (46.4\% vs $34.3 \%)$, and were almost twice as likely to reach their goal for $\mathrm{HbA}_{1 \mathrm{c}}(48.6 \%$ vs $27.6 \%)$, as previously reported. ${ }^{17}$ This improvement was limited to the larger of the 2 clinic sites, with no significant difference between arms at the smaller clinic site.

\section{Observational Study Period (12 to 24 Months)}

Before the start of the RCT, the study team decided with partnering clinics to offer health coaching to the usual-care patients and to support clinic sites in developing the internal capacity to maintain coaching after completion of the 12-month RCT. All patients from the usual-care arm with diabetes, hypertension, or hyperlipidemia out of goal range at 12 months were offered a limited amount of health coaching, resulting in 56 usual-care patients receiving post-RCT coaching. The limited coaching was in the same format and provided by the same health coaches as the original intervention, but for a shorter period (less than 6 months) because support funds were limited. Patients who received this limited coaching participated in an average of 4.0 health coaching interactions for an average total of 444.3 (SD 331.3) minutes. This was significantly less than the mean of 13.5 interactions and 648.9 minutes received by patients in the health coaching arm of the RCT. Usual-care patients who had achieved their clinical goals and patients from the RCT health coaching arm did not receive coaching during the post-RCT period, although clinic staff received training in health coaching during this period.

\section{The Current Study}

At 24 months after enrollment in the original RCT, we conducted an observational survey of all participants. The purpose of this 24-month follow-up was not to make a second round of comparisons between the arms of the RCT, as such a comparison would have little meaning given that selected patients from the usualcare arm received non-randomized post-intervention coaching. Rather, the aim of the 24-month follow-up was to describe the natural history of patients from within each arm after the RCT. We compared outcomes at 12 and 24 months within each of 3 groups: participants from the RCT health coaching arm, participants from the usual care arm who received postRCT coaching, and participants from the usual care arm who never received coaching.

Study staff attempted to contact all patients enrolled in the randomized trial by phone between 23 and 28 months from enrollment, making up to 9 calls if necessary, and arranged to meet those interested in the observational follow-up study. After gaining informed consent, study staff obtained 24 -month clinical measures. Participants in the 24-month observational study received $\$ 20$ in recognition of their time commitment.

\section{Measures}

Clinical measures obtained at baseline, 12, and 24 months included $\mathrm{HbA}_{1 \mathrm{c}}$, blood pressure, lipids, weight, and height. We used the clinical measures closest in time to 12 and 24 months from baseline, respectively. If there was no measure available within a 5 -month window between 1 month before to 4 months after the target date, the measure was considered to be missing. Full details of protocols for obtaining each measure have been published previously. ${ }^{18}$ The primary clinical outcome at both 12 and 24 months was the proportion of patients achieving control for at least 1 of the conditions uncontrolled at RCT entry, defined as having $\mathrm{HbA}_{1 \mathrm{c}}$ less than $8 \%$, LDL less than $130 \mathrm{mg} / \mathrm{dL}$ for patients without diabetes and less than $100 \mathrm{mg} / \mathrm{dL}$ for those with diabetes, and SBP less than $140 \mathrm{~mm} \mathrm{Hg}$ for patients without diabetes and less than 130 for those with diabetes. Secondary clinical outcomes included reaching composite goal for all clinical conditions and for each individual condition the individual participants were eligible for on study entry. Additional outcomes were changes in mean $\mathrm{HbA}_{1 \mathrm{c}}, \mathrm{LDL}$, and SBP.

\section{Statistical Analysis}

The proportions of participants reaching composite and condition-specific goals were evaluated using McNemar's $\chi^{2}$ test for differences between 12 and 24 months within study arms and $\chi^{2}$ tests for differences between study arms. Paired $t$-tests were used for continuous outcomes within study arms and 2-sample independent $t$-tests for continuous outcomes between study arms. Additional subgroup analyses were conducted comparing participants in the usual-care arm who received post-RCT health coaching and those who did not. Chi-square and $t$-tests were conducted to test for baseline differences between study arms. Logistic regression models examined potential differences between dropouts (participants without clinical outcome data at the 12- or 24-month follow-up) and continuing participants. All statistical analysis was performed using Stata version 13.1 (StataCorp LP).

\section{RESULTS}

Of the original 441 participants at RCT entry, 290 (65.8\%) provided clinical outcome data at both 12 months and 24 months (157 patients from the health coaching arm and 133 from the usual-care arm) (Figure 1). There were no significant baseline differences in patient characteristics by study arm (Table 1). In 
Table 1. Baseline Participant Characteristics From Original RCT and Current 24 Month Follow-Up, Overall and by Study Arm

\begin{tabular}{|c|c|c|c|c|}
\hline & $\begin{array}{l}\text { All Participants } \\
\text { at Baseline } \\
\text { (n= 441) }\end{array}$ & $\begin{array}{l}\text { All Participants } \\
\text { in 12- and } \\
\text { 24-Month Analysis } \\
(n=290)\end{array}$ & $\begin{array}{l}\text { Usual Care Arm } \\
\text { Participants in 12- and } \\
\text { 24-Month Analysis } \\
(n=133)\end{array}$ & $\begin{array}{c}\text { Health Coaching Arm } \\
\text { Participants in 12- and } \\
\text { 24-Month Analysis } \\
(n=157)\end{array}$ \\
\hline \multicolumn{5}{|l|}{ Demographic Characteristics } \\
\hline \multicolumn{5}{|l|}{ Clinic site, \% (No.) } \\
\hline Clinic site $A$ & $75.3(332)$ & $76.2(221)$ & $77.4(103)$ & $75.2(118)$ \\
\hline Clinic site B & $24.7(109)$ & $23.8(69)$ & $22.6(30)$ & $24.8(39)$ \\
\hline Age, mean (SD), y & $52.7(11.1)$ & $53.2(10.8)$ & $52.5(11.5)$ & $53.7(10.2)$ \\
\hline Female sex, \% (No.) & $55.3(244)$ & $56.6(164)$ & $62.4(83)$ & $51.6(81)$ \\
\hline $\begin{array}{l}\text { Married or in long-term relation- } \\
\text { ship, \% (No.) }\end{array}$ & $53.1(234)$ & $51.97(150)$ & $57.1(76)$ & $47.1(74)$ \\
\hline Born in United States, \% (No.) & $25.6(113)$ & $26.6(77)$ & $25.6(34)$ & $27.4(43)$ \\
\hline Years in United States, mean (SD) ${ }^{a}$ & $18.2(11.2)$ & $18.6(11.0)$ & $17.4(11.6)$ & $19.6(10.4)$ \\
\hline \multicolumn{5}{|l|}{ Primary language, \% (No.) } \\
\hline English & $27.7(122)$ & $28.3(82)$ & $27.1(36)$ & $29.3(46)$ \\
\hline Spanish & $68.7(303)$ & $69.0(200)$ & $70.7(94)$ & $67.5(106)$ \\
\hline Other & $3.6(16)$ & $2.8(8)$ & $2.3(3)$ & $3.2(5)$ \\
\hline \multicolumn{5}{|l|}{ Race/Ethnicity, \% (No.) } \\
\hline Asian/Pacific Islander & $4.1(18)$ & $3.5(10)$ & $4.5(6)$ & $2.6(4)$ \\
\hline African American & $19.0(84)$ & $20.0(58)$ & $19.6(26)$ & $20.4(32)$ \\
\hline Latino or Hispanic & 70.1 (309) & $69.7(202)$ & $71.4(95)$ & $68.2(107)$ \\
\hline White & $2.5(11)$ & $2.8(8)$ & $3.0(4)$ & $2.6(4 /)$ \\
\hline Other & $4.3(19)$ & $4.1(12)$ & $3.0(4)$ & $6.4(10)$ \\
\hline \multicolumn{5}{|l|}{ Working status, \% (No.) } \\
\hline Employed full time & $18.6(82)$ & $18.3(53)$ & $17.3(23)$ & $19.1(30)$ \\
\hline Employed part time & $25.6(113)$ & $27.9(81)$ & $29.6(38)$ & $27.4(43)$ \\
\hline Homemaker & $13.8(61)$ & $13.5(39)$ & $16.5(22)$ & $10.8(17)$ \\
\hline Unemployed & $16.1(71)$ & $14.5(42)$ & $16.5(22)$ & $12.7(20)$ \\
\hline Retired, Disabled, SSI, other & 25.9 (114) & $25.9(75)$ & $21.1(28)$ & $29.9(47)$ \\
\hline \multicolumn{5}{|l|}{ Education, \% (No.) } \\
\hline$<5$ th grade & $22.7(100)$ & $23.1(67)$ & $26.3(35)$ & $20.4(32)$ \\
\hline 6 th to 8 th grade & $21.1(93)$ & $21.0(61)$ & $19.6(26)$ & $22.3(35)$ \\
\hline Some high school & $13.4(59)$ & $13.1(38)$ & $12.0(16)$ & $14.0(22)$ \\
\hline High school graduate or GED & $17.7(78)$ & $16.9(49)$ & $13.5(18)$ & $19.8(31)$ \\
\hline Some college & $15.6(69)$ & $15.9(46)$ & $19.6(26)$ & $12.7(20)$ \\
\hline College graduate & $9.5(42)$ & $10.0(29)$ & $9.0(12)$ & $10.8(17)$ \\
\hline \multicolumn{5}{|l|}{ Income, \% (No.) } \\
\hline$<\$ 5,000$ & $34.0(150)$ & $33.5(97)$ & $30.8(41)$ & $35.7(56)$ \\
\hline$\$ 5,000-\$ 10,000$ & $24.3(107)$ & $22.8(66)$ & $21.8(29)$ & $23.6(37)$ \\
\hline$\$ 10,000-\$ 20,000$ & $29.5(130)$ & $33.5(97)$ & $33.1(44)$ & $33.8(53)$ \\
\hline$>\$ 20,000$ & $12.2(54)$ & $10.3(30)$ & $14.3(19)$ & $7.0(11)$ \\
\hline $\begin{array}{l}\text { No. primary care visits in year } \\
\text { before study, mean (SD) }\end{array}$ & $5.4(3.9)$ & $5.2(3.9)$ & $5.2(4.2)$ & $5.3(3.6)$ \\
\hline \multicolumn{5}{|l|}{ Baseline Clinical Characteristics } \\
\hline BMI, mean (SD), kg/m2 & $31.6(6.6)$ & $31.7(6.0)$ & $31.7(5.7)$ & $31.8(6.2)$ \\
\hline $\mathrm{HbA}_{1 \mathrm{c}}$, mean $(\mathrm{SD}), \% \mathrm{~b}$ & $9.9(1.5)$ & $9.8(1.5)$ & $10.0(1.5)$ & $9.6(1.4)$ \\
\hline $\mathrm{LDL}$, mean (SD), mg/dL ${ }^{b}$ & $146.5(34.9)$ & $143.1(32.2)$ & $143.9(32.5)$ & $142.6(32.3)$ \\
\hline $\mathrm{SBP}$, mean (SD), $\mathrm{mm} \mathrm{Hg}^{\mathrm{b}}$ & $158.9(15.1)$ & $159.3(15.4)$ & $160.4(16.6)$ & $158.3(14.2)$ \\
\hline \multicolumn{5}{|l|}{ Uncontrolled at baseline, \% (No.) } \\
\hline For 1 condition & $72.6(320)$ & $74.5(216)$ & $75.9(101)$ & $73.3(115)$ \\
\hline For 2 conditions & $23.6(104)$ & $22.1(64)$ & $21.1(28)$ & $22.9(36)$ \\
\hline For 3 conditions & $3.9(17)$ & $3.5(10)$ & $3.0(4)$ & $3.8(6)$ \\
\hline For $\mathrm{HbA}_{1 \mathrm{c}}$ & $35.8(158)$ & $35.5(103)$ & $33.1(44)$ & $37.6(59)$ \\
\hline For SBP & $43.5(192)$ & $44.8(130)$ & $46.6(62)$ & $43.3(68)$ \\
\hline For LDL & $51.9(229)$ & $48.6(141)$ & $47.4(63)$ & $49.7(78)$ \\
\hline \multicolumn{5}{|c|}{$\mathrm{HbA}_{\mathrm{lc}}=$ hemoglobin $\mathrm{A}_{\mathrm{l} ;} \mathrm{LDL}=$ low-density lipoprotein; SBP = systolic blood pressure; SSI = Supplemental Security Income } \\
\hline \multicolumn{5}{|c|}{$\begin{array}{l}\text { a For participants born outside the United States. } \\
\text { b Includes only patients eligible for the study on this measure (158 at baseline, and } 103 \text { at } 24 \text { months for } \mathrm{HbA}_{1 c i} 192 \text { at baseline and } 130 \text { at } 24 \text { months for SBP; } 218 \text { at } \\
\text { baseline, and } 141 \text { at } 24 \text { months for LDL). }\end{array}$} \\
\hline \multicolumn{5}{|c|}{ Note: We found no significant differences between health coaching and usual care groups at 24 months. } \\
\hline
\end{tabular}


line with the previously reported 12 month $\mathrm{RCT}_{1}{ }^{17}$ there was a significantly higher dropout in the usualcare arm than the intervention arm $(55.6 \%$ vs $44.4 \%$, $P=.05)$.

\section{RCT Health Coaching Arm}

Outcome measures for patients from the health coaching arm of the RCT showed little change between 12 and 24 months (Table 2, Figure 2). Effectively the same proportion of patients met the primary composite outcome of achieving at least 1 clinical goal at 12 months $(47.1 \%)$ as at 24 months $(45.9 \%)(P=.80)$. Similarly, almost the same proportion achieved the secondary outcome of meeting all clinical goals for which they were eligible on study entry at 12 months (35.7\%) and 24 months $(33.8 \%)(P=.66)$. A similar pattern was seen for SBP and LDL. The proportion achieving goal $\mathrm{HbA}_{\mathrm{lc}}(<8 \%)$ declined significantly between 12 and 24 months from $53.4 \%$ to $36.2 \%$ ( $P=.03$ ).

Of the 74 patients in the health coaching arm of the RCT who achieved the primary outcome of at least 1 clinical goal at 12 months, $43(58.1 \%)$ maintained the outcome at 24 months. Of the 83 patients who were not at goal at 12 months, an additional 29 (34.9\%) achieved goal at 24 months.

\section{Usual-Care Arm: Coached Post-RCT and Never Coached}

Fifty-six of the 133 patients from the usual care arm (42.1\%) received health coaching in the post-RCT period, with 48 (36.1\%) having clinical data available at 12 and 24 months. Comparison of usual-care patients who received limited post-RCT coaching with those who did not revealed notable differences. For patients in the usual care arm who received post-RCT coaching, the proportion achieving the primary out- come of at least 1 clinical goal increased from $10.4 \%$ at 12 months to $33.3 \%$ at 24 months (Table 3). For the usual-care patients who never received coaching, the proportion was essentially unchanged, from $45.9 \%$ at 12 months to $48.2 \%$ at 24 months, indicating that most of the improvement seen in the usual-care arm occurred among the patients who received coaching. Similarly, for most secondary outcomes, there were improvements in usual-care patients who received post-RCT coaching and minimal change in usual-care patients who never received coaching between 12 and 24 months.

\section{DISCUSSION}

This observational survey 1 year after a 12 -month RCT provides a rare chance to follow patients after a health coaching intervention in an ethnic minority, safety-net population. The primary intent of the current study was to learn whether the positive effects of health coaching persisted after coaching was stopped. While our initial study found that a 12 -month health coaching intervention significantly improved achievement of clinical goals, we now know that up to 1 year after health coaching, patients in the health coaching intervention arm experienced only minimal declines in clinical goals, with the exception of $\mathrm{HbA}_{1 \mathrm{c}}$, implying overall maintenance of health coaching effects. Very few studies have this length of follow-up; in our review of the literature we found only 2 RCTs of health coaching that had greater than 6 months follow-up time. One study was a single-blind RCT of a cardiovascular secondary prevention program with telephone coaching for 3 months. Follow-up 4 years after the intervention showed improved cardiovascular risk factors. ${ }^{14}$ Another cluster-randomized trial of 1-year peer telephone coaching for parents of children with asthma showed reduced ED visits in the intervention arm compared with usual care at 24 months. ${ }^{16}$

The finding in our study showing that most of the improvements seen at 12 months in the RCT health-coaching arm were maintained at 24 months is encouraging. The regression in achievement of goal $\mathrm{HbA}_{1 \mathrm{c}}$ at 24 months in the health coaching arm suggests that maintaining gains in diabetes management may require continuing support, for example through "booster coaching." 
Figure 2. Outcome measures at baseline, 12, and 24 months for patients in the health coaching arm of the 12-month randomized controlled trial.
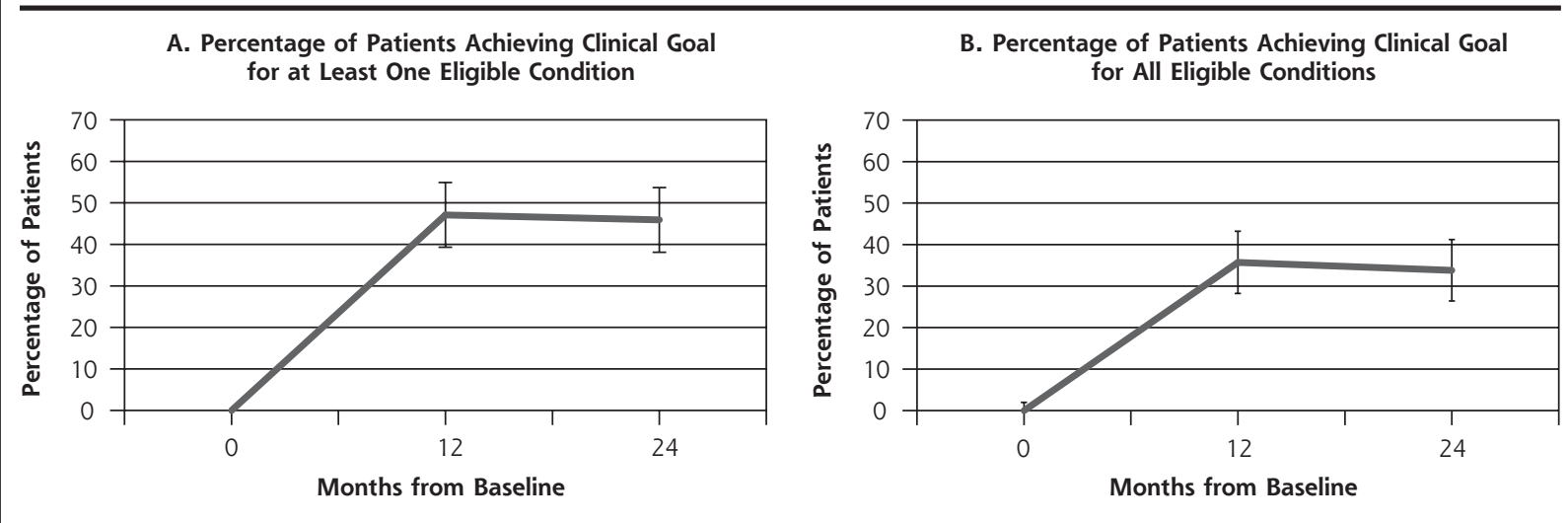

C. Percentage of Patients Achieving Clinical Goal for $\mathrm{HbA}_{1 \mathrm{c}}$

D. Average $\mathrm{HbA}_{1 \mathrm{c}}$ for Eligible Patients
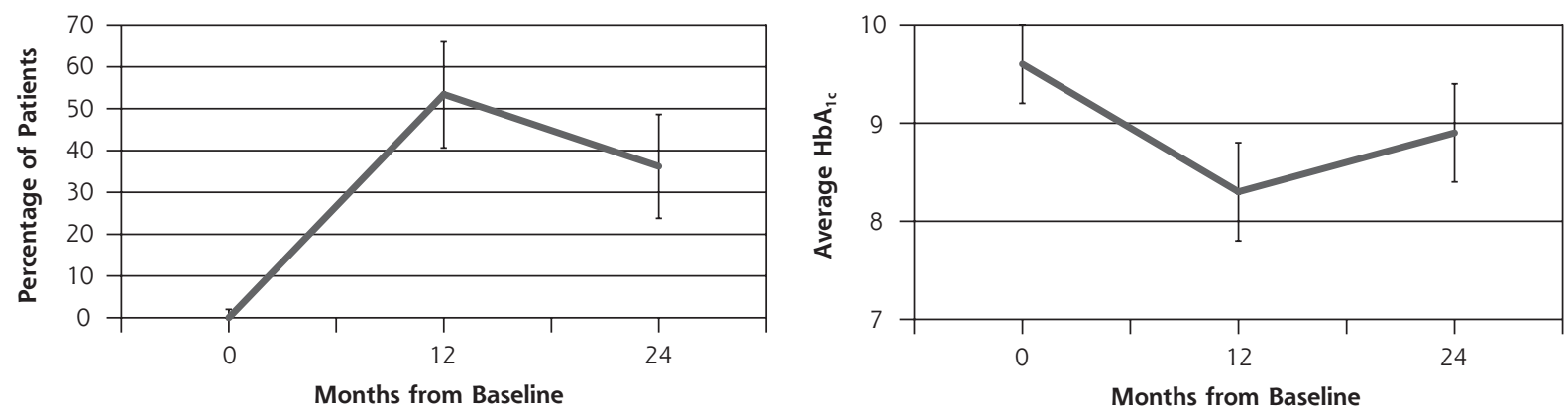

E. Percentage of Patients Achieving Clinical Goal for LDL
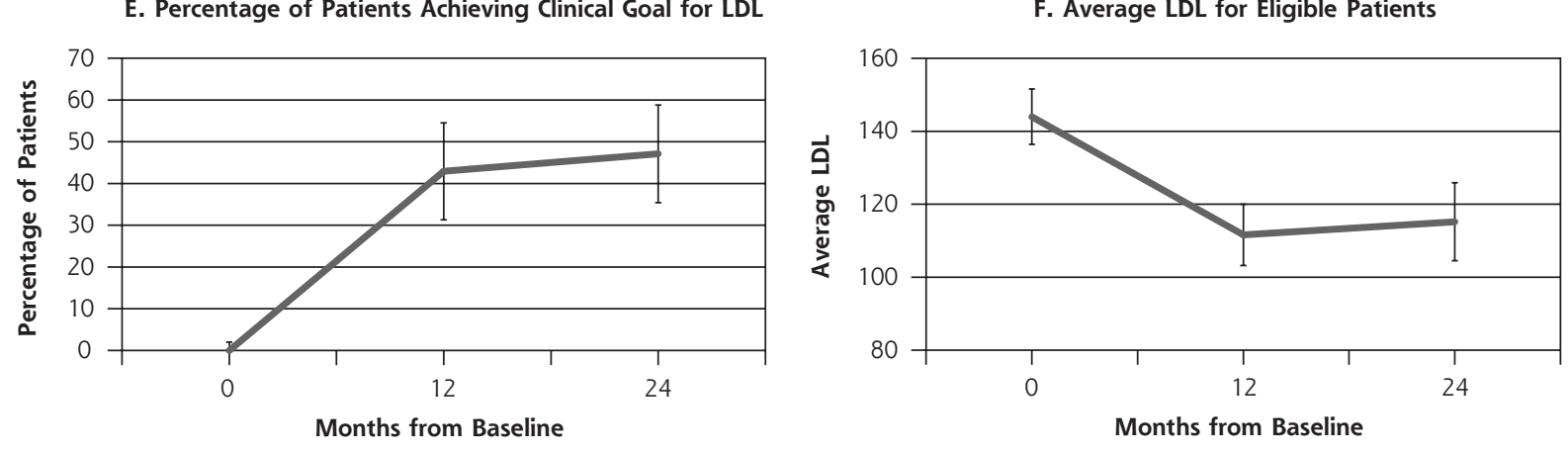

G. Percentage of Patients Achieving Clinical Goal for SBP

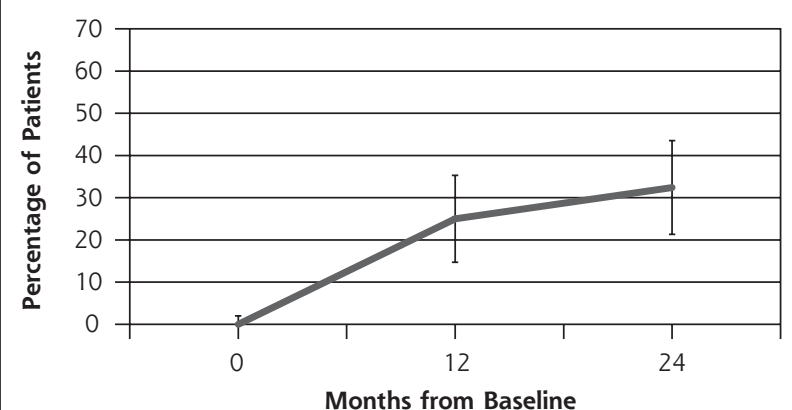

H. Average SBP for Eligible Patients

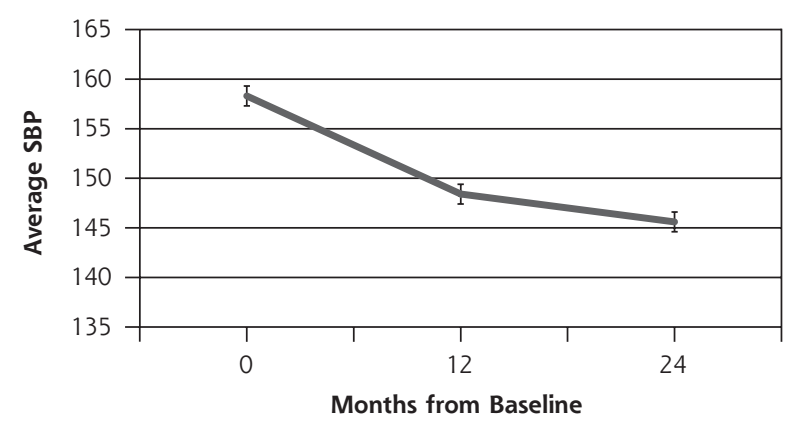

$\mathrm{HbA}_{1 \mathrm{c}}=$ hemoglobin $\mathrm{A}_{1 \mathrm{c}} ; \mathrm{LDL}=$ low-density lipoprotein; $\mathrm{SBP}=$ systolic blood pressure 
Table 3. Subgroup Analysis of Usual Care Arm, Comparing Those Who Received Post-RCT Coaching vs Those Not Coached

\begin{tabular}{|c|c|c|c|c|c|c|}
\hline \multirow[b]{2}{*}{ Outcome } & \multicolumn{3}{|c|}{$\begin{array}{l}\text { Usual Care Arm Participants } \\
\text { Coached Post-RCTa }\end{array}$} & \multicolumn{3}{|c|}{$\begin{array}{l}\text { Usual Care Arm Participants } \\
\text { Not Coached Post-RCT }\end{array}$} \\
\hline & Baseline & 12 months & 24 months & Baseline & 12 months & 24 months \\
\hline $\begin{array}{l}\text { Composite } 1 \text {, meeting } 1 \\
\text { goal, \% (No.) }\end{array}$ & 0 & $\begin{array}{r}10.4(5) \\
n=48\end{array}$ & $\begin{array}{c}33.3(16) \\
n=48\end{array}$ & 0 & $\begin{array}{c}45.9(39) \\
n=85\end{array}$ & $\begin{array}{c}48.2(41) \\
n=85\end{array}$ \\
\hline $\begin{array}{l}\text { Composite 2, meeting all } \\
\text { goals, \% (No.) }\end{array}$ & 0 & $\begin{array}{l}4.2(2) \\
n=48\end{array}$ & $\begin{array}{c}25.0(12) \\
n=48\end{array}$ & 0 & $\begin{array}{c}35.3(30) \\
n=85\end{array}$ & $\begin{array}{c}37.7(32) \\
n=85\end{array}$ \\
\hline $\mathrm{HbA}_{1 \mathrm{c}}$ at goal, \% (No.) & 0 & $\begin{array}{l}4.0(1) \\
n=25\end{array}$ & $\begin{array}{r}24.0(6) \\
n=25\end{array}$ & 0 & $\begin{array}{c}55.6(10) \\
n=18\end{array}$ & $\begin{array}{r}44.4(8) \\
n=18\end{array}$ \\
\hline LDL at goal, \% (No.) & 0 & $\begin{array}{r}14.3(3) \\
n=21\end{array}$ & $\begin{array}{r}38.1(8) \\
n=21\end{array}$ & 0 & $\begin{array}{c}43.2(16) \\
n=37\end{array}$ & $\begin{array}{c}56.8(21) \\
\mathrm{n}=37\end{array}$ \\
\hline SBP at goal, \% (No.) & 0 & $\begin{array}{l}6.3(1) \\
\mathrm{n}=16\end{array}$ & $\begin{array}{r}18.8(3) \\
n=16\end{array}$ & 0 & $\begin{array}{c}37.0(17) \\
\mathrm{n}=46\end{array}$ & $\begin{array}{c}32.6(15) \\
n=46\end{array}$ \\
\hline $\mathrm{HbA}_{1 c}$, mean (SD), \% & $\begin{array}{l}10.2(1.3) \\
n=25\end{array}$ & $\begin{array}{c}10.2(1.8) \\
n=25\end{array}$ & $\begin{array}{l}9.7(1.8) \\
n=25\end{array}$ & $\begin{array}{l}9.6(1.5) \\
n=18\end{array}$ & $\begin{array}{l}8.3(1.6) \\
n=18\end{array}$ & $\begin{array}{l}8.9(2.1) \\
n=18\end{array}$ \\
\hline $\mathrm{LDL}$, mean $(\mathrm{SD}), \mathrm{mg} / \mathrm{dL}$ & $\begin{array}{c}136.7(35.2) \\
n=21\end{array}$ & $\begin{array}{c}130.7(37.2) \\
n=21\end{array}$ & $\begin{array}{c}116.0(37.1) \\
\mathrm{n}=21\end{array}$ & $\begin{array}{c}149.8(30.1) \\
n=37\end{array}$ & $\begin{array}{c}119.3(34.3) \\
\mathrm{n}=37\end{array}$ & $\begin{array}{c}103.0(34.8) \\
\mathrm{n}=37\end{array}$ \\
\hline SBP, mean (SD), mm Hg & $\begin{array}{c}162.8(14.5) \\
n=16\end{array}$ & $\begin{array}{c}158.8(15.9) \\
n=16\end{array}$ & $\begin{array}{l}154.3(25.8) \\
n=16\end{array}$ & $\begin{array}{l}159.6(17.3) \\
n=46\end{array}$ & $\begin{array}{l}146.3(17.8) \\
n=46\end{array}$ & $\begin{array}{c}148.8(20.2) \\
n=46\end{array}$ \\
\hline
\end{tabular}

The patients in the usual care arm who received post-RCT coaching between 12 and 24 months showed improvement in all outcomes. Patients from the usual-care arm of the original RCT who reached goal at 12 months, and who therefore did not receive post-RCT coaching, experienced only small changes between 12 and 24 months. While the improvement among usual-care patients receiving post-RCT coaching is intriguing, this subgroup received coaching in a non-randomized fashion and on average were under poorest control, meaning they likely had the most to gain from some amount of coaching and were more likely to experience improvement due to regression to the mean. Given the observational nature of this follow-up and purposeful assignment of coaching based on clinical parameters, it is not feasible to perform multivariate comparison between the usual-care subgroups; therefore, interpretations of the role of limited health coaching are speculative, with multiple implications possible.

Clinic-level changes in care may also explain some of the maintenance of gains in patients who received coaching during the RCT and improvements in the usual-care group, including those who never received coaching. There may have been overall improvements in care due to quality improvement initiatives, training received at the end of the study, or a "spillover effect" where providers exposed to the intervention incorporated health coaching principles into their care for usual-care patients.
Limitations of this study include the fact that this follow-up is an observational study, making our interpretations speculative. Not surprisingly in a 2-year follow-up period among a safety-net population, there was considerable attrition (34.2\%) with higher dropout in the usual-care arm. Comparison of usual-care patients who received post-RCT health coaching with those who did not was limited by small sample sizes in the subgroups.

This observational study following a randomized controlled trial provides an important look at what happens to a safety-net population that received health coaching for cardiovascular risk factors. The original RCT showed that health coaching is an effective intervention in low-resource settings. The current study shows that most clinical effects are largely maintained up to a year after receiving coaching. Health coaching by medical assistants may provide a cost-effective way to provide self-management support with effects that are largely sustainable over time.

To read or post commentaries in response to this article, see it online at http://www.annfammed.org/content/14/3/200.

Keywords: primary care; patient-centered care; chronic care; patient self-care support; health promotion; disease prevention; health behavior change; special population; underserved patients; minority health; practice-based research

Submitted June 26, 2015; submitted, revised, December 2, 2015; accepted December 15, 2015.

Funding support: This study was supported by a grant from the Gordon and Betty Moore Foundation. Dr Sharma was supported by 
National Research Service Award T32HP19025. The funders had no influence on the design, conduct, or analysis of the study.

Prior presentations: Poster presented at University of California Family Medicine Department of Family Research Annual Rodnick Colloquium; May 28. 2015; San Francisco, California; and North American Primary Care Research Group; October 24-28, 2015; Cancun, Mexico.

Acknowledgments: The authors gratefully acknowledge the work of health coaches Christina Araujo and Adriana Najmabadi, study research assistants Denise DeVore, Marissa Pimental, and Camille Prado; as well as the support of the leadership, patients and staff of Mission Neighborhood Health Center and Southeast Health Center.

- Supplementary materials: Available at http://www.AnnFamMed. org/content/14/3/200/suppl/DC1/.

\section{References}

1. Narayan KM, Boyle JP, Thompson TJ, Sorensen SW, Williamson DF. Lifetime risk for diabetes mellitus in the United States. JAMA. 2003;290(14):1884-1890.

2. Wang TJ, Vasan RS. Epidemiology of uncontrolled hypertension in the United States. Circulation. 2005;112(11):1651-1662.

3. Ghandehari H, Kamal-Bahl S, Wong ND. Prevalence and extent of dyslipidemia and recommended lipid levels in US adults with and without cardiovascular comorbidities: the National Health and Nutrition Examination Survey 2003-2004. Am Heart J. 2008;156(1): 112-119.

4. Hajjar I, Kotchen TA. Trends in prevalence, awareness, treatment, and control of hypertension in the United States, 1988-2000. JAMA. 2003;290(2):199-206.

5. Mensah GA, Brown DW. An overview of cardiovascular disease burden in the United States. Health Aff (Millwood). 2007;26(1):38-48.

6. Cooper R, Cutler J, Desvigne-Nickens P, et al. Trends and disparities in coronary heart disease, stroke, and other cardiovascular diseases in the United States: findings of the national conference on cardiovascular disease prevention. Circulation. 2000;102(25):3137-3147.

7. Falkner B, Cossrow ND. Prevalence of metabolic syndrome and obesity-associated hypertension in the racial ethnic minorities of the United States. Curr Hypertens Rep. 2014;16(7):449.

8. Baxter RJ, Mechanic RE. The status of local health care safety nets. Health Aff (Millwood). 1997;16(4):7-23.
9. Bennett HD, Coleman EA, Parry C, Bodenheimer T, Chen EH, Health coaching for patients with chronic illness. Fam Pract Manag. 2010;17(5):24-29.

10. Thom DH, Ghorob A, Hessler D, De Vore D, Chen E, Bodenheimer TA. Impact of peer health coaching on glycemic control in lowincome patients with diabetes: a randomized controlled trial. Ann Fam Med. 2013;11(2):137-144.

11. Redfern J, Briffa T, Ellis E, Freedman SB. Choice of secondary prevention improves risk factors after acute coronary syndrome: 1-year follow-up of the CHOICE (Choice of Health Options In prevention of Cardiovascular Events) randomised controlled trial. Heart. 2009;95(6):468-475.

12. Margolius D, Bodenheimer $T$, Bennett $H$, et al. Health coaching to improve hypertension treatment in a low-income, minority population. Ann Fam Med. 2012;10(3):199-205.

13. Jelinek $M$, Vale $M J$, Liew $D$, et al. The COACH program produces sustained improvements in cardiovascular risk factors and adherence to recommended medications-two years follow-up. Heart Lung Circ. 2009;18(6):388-392.

14. Garbutt JM, Yan Y, Highstein G, Strunk RC. A cluster-randomized trial shows telephone peer coaching for parents reduces children's asthma morbidity. J Allergy Clin Immunol. 2015;135:1163-70.e1-2.

15. Becker A, Leonhardt C, Kochen MM, et al. Effects of two guideline implementation strategies on patient outcomes in primary care: a cluster randomized controlled trial. Spine (Phila Pa 1976). 2008;33 (5):473-480.

16. Neubeck L, Freedman SB, Briffa T, Bauman A, Redfern J. Four-year follow-up of the Choice of Health Options In prevention of Cardiovascular Events randomized controlled trial. Eur J Cardiovasc Prev Rehabil. 2011;18(2):278-286.

17. Willard-Grace R, Chen EH, Hessler D, et al. Health coaching by medical assistants to improve control of diabetes, hypertension, and hyperlipidemia in low-income patients: a randomized controlled trial. Ann Fam Med. 2015;13(2):130-138.

18. Willard-Grace R, DeVore D, Chen EH, Hessler D, Bodenheimer T, Thom DH. The effectiveness of medical assistant health coaching for low-income patients with uncontrolled diabetes, hypertension, and hyperlipidemia: protocol for a randomized controlled trial and baseline characteristics of the study population. BMC Fam Pract. 2013;14:27.

19. University of California San Francisco Center for Excellence in Primary Care. Health coaching. http://cepc.ucsf.edu/health-coaching. Accessed Oct 11, 2015. 